\title{
Endocrine Pathology Society Hubert Wolfe Award for 2021: Call for Nominations
}

Published online: 23 October 2021

๑) Springer Science+Business Media, LLC, part of Springer Nature 2021
The Endocrine Pathology Society invites nominations for the Hubert Wolfe Award for 2021. This award, established in memory of Dr. Hubert Wolfe, is awarded annually at the discretion of the Endocrine Pathology Society to honor an outstanding original research paper in the field of endocrine pathology published during the previous calendar year by a pathologist in training. The award and accompanying prize will be awarded at the Endocrine Pathology Society's annual meeting in March 2022.

Nominations should be sent to the Wolfe award committee.

Ronald A. DeLellis, M.D.

Lifespan Academic Medical Center

Email: rdelellis@ lifespan.org

Arthur S. Tischler, M.D.

Tufts Medical Center

Email: atischler@tuftsmedicalcenter.org
Ronald Ghossein, M.D.

Memorial Sloan Kettering Cancer Center

Email: ghosseir@MSKCC.ORG

Ozgur Mete, M.D.

University Health Network, University of Toronto

Email: ozgur.mete2@uhn.ca

For additional information please visit the Endocrine Pathology Society website at https://endocrinepathology.org.

Publisher's Note Springer Nature remains neutral with regard to jurisdictional claims in published maps and institutional affiliations. 